\title{
Screen time evaluation, association with obesity, and cardiorespiratory fitness among children aged $10-12$ years
}

\author{
Sharayu Agre ${ }^{1}$, Ronika Agrawal' ${ }^{2}$ Arwa Alirajpurwala ${ }^{3}$ \\ From ${ }^{1}$ Assistant Professor, ' $P$ rincipal and Professor, Department of Physiotherapy, Maharashtra Medical Education and Research Centre, \\ M. A. Rangoonwala College of Physiotherapy and Research, Pune, ${ }^{3}$ Maharashtra University of Health Sciences, Nashik, Maharashtra, India
}

Correspondence to: Dr. Sharayu Agre, Maharashtra Medical Education and Research Centre, M. A. Rangoonwala College of Physiotherapy and Research, Azam Campus, Pune, Maharashtra, India. E-mail: asharayu@gmail.com

Received - 04 March 2019

Initial Review - 04 March 2019

Accepted - 25 June 2019

\begin{abstract}
Background: Screen time (ST) is defined as the viewing or use of anything with a screen including TV, DVDs, video games, and computers. They reduce time for outdoor activities resulting in less physical work. Thus, it is necessary to establish a relationship between ST and obesity and its association with cardiorespiratory illnesses. Objective: The objective of this study was to determine the correlation of ST with obesity and cardiorespiratory fitness ( $\left.\mathrm{VO}_{2} \max \right)$ among children aged 10-12 years. Materials and Methods: Body mass index (BMI), waist-hip ratio (WHR), and $\mathrm{VO}_{2}$ max of each child were calculated. The children were also given a questionnaire consisting of 45 activities categorized into moderate- and vigorous-intensity physical activities and leisure activities which they usually perform in the entire week. Thus, total duration for all activities performed in a day was summed. Data were analyzed for correlation. Results: The average age of students was 11.09 years. Average BMI of males was $16.52 \pm 3.67 \mathrm{~kg} / \mathrm{m}^{2}$. Average BMI for females was $17.12 \pm 2.46 \mathrm{~kg} / \mathrm{m}^{2}$. Average $\mathrm{VO}_{2}$ max for students was $35.83 \mathrm{ml} / \mathrm{kg} / \mathrm{min}$. ST for students was ranging from $40 \mathrm{~min}$ to $190 \mathrm{~min}$. Positive correlation between ST and BMI of children was $r=0.66$ which suggests as ST increases BMI increases. Similar trend was seen with WHR and $\mathrm{VO}_{2}$ max, suggesting that as $\mathrm{ST}$ increases endurance decreases and risk for cardiorespiratory disease increases. Conclusion: Increased ST in children increases the chances of obesity and reduces the level of cardiorespiratory fitness.
\end{abstract}

Key words: 20-m multistage Shuttle run test, Obesity in children, Screen time

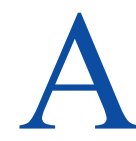

ccording to the WHO, obesity is defined as abnormal or excessive fat accumulation that might impair health [1].

In India, the proportion of overweight children increased from $4.94 \%$ in 2003 to $6.57 \%$ in 2005 , demonstrating the time trend of this rapidly growing epidemic [2]. The prevalence of obesity in school-going children was $19.3 \%$ in studies reported after 2010 [3]. Among the key lifestyle behaviors, little physical activity and high screen time (ST) have mainly been attributed to childhood obesity, worldwide [4]. Weight gain occurs when intake is greater than the energy expenditure [5]. Obesity is a strong predictor of morbidity with central obesity associated with insulin resistance, dyslipidemia, and hypertension which are all independent risk factors for cardiovascular disease [6].

Physical activity is defined as the bodily movement that is produced by the contraction of the skeletal muscles and that substantially increases the energy expenditure [7]. Watching television and playing computer games are associated with increased prevalence of obesity. ST is defined as the viewing or use of anything with a screen including TV, DVDs, video games, and computers. Due to the availability of new media technology, for example, cell phone and computer, ST duration has increased among children. Long periods of ST mean less opportunity for active, outdoor and creative play, less healthy eating habits, memory, and thinking skills, thus suggesting that ST activities are physically and cognitively sedentary [7].

Associations between television viewing, media use, and children's weight status characteristics have been studied quite frequently [8]. Aerobic fitness contributes to health and is essential component of youth fitness testing [9]. Cardiorespiratory fitness is related to the ability to perform large muscle, dynamic, and moderate- to high-intensity exercise for prolonged periods $[7,10,11]$. The aim of the study was to determine the correlation of ST with obesity and cardiorespiratory fitness among children aged 10-12 years.

\section{MATERIALS AND METHODS}

After receiving the approval from the ethical committee and obtaining consent from the school principal, the study was conducted in government and private schools in Pune. It was a cross-sectional study, in which 568 children (332 males and 236 females) were recruited over the period of 3 months with convenient sampling. The student consent form and parents' permission letter was obtained.

Healthy children aged 10-12 years, both males and females, were recruited in the study. Children suffering from any respiratory 
conditions (asthma, tuberculosis, etc.), cardiac conditions (congenital heart diseases), neurological deficit (poliomyelitis, etc.), or musculoskeletal disorders (muscular pain, fractures, or any other related conditions) were excluded from the study.

\section{Outcome Measures and Their Operational Definitions}

Body mass index (BMI) was calculated by the formula: Weight in kilograms divided by the square of height in meters. A high $\mathrm{BMI}$ can be an indicator of high body fatness. The waist-hip ratio (WHR) is the dimensionless ratio of the circumference of the waist to that of the hips. WHR is a quick measure of the fat distribution that may help indicate a person's overall health. People who carry more weight around their middle than their hips may be at a higher risk of developing certain health conditions. $\mathrm{VO}_{2}$ max, also known as maximal oxygen uptake, is the measurement of the maximum amount of oxygen, a person can utilize during intense exercise. This is a good indicator of cardiovascular fitness. ST by leisure activity questionnaire (Children's Leisure Activity Questionnaire [CLASS]), is a scale through which persons total time in front of screen, for example, phone, TV, and computer can be calculated.

Brief explanation of the procedure was given to each child. Parents and children were asked to sign a written consent before their participation. BMI was calculated, waist and hip circumference was measured with measuring tape, and ratio of waist-to-hip circumference was taken. Children were made to perform a 20-m multistage Shuttle run test. $\mathrm{VO}_{2} \max$ was determined using linear model 2. Children were then asked to fill the CLASS questionnaire.

\section{0-m Multistage Shuttle Run Test}

A distance of $20 \mathrm{~m}$ was marked. Children were made to run from the start to the end point, while the metronome was being played on the speaker. Children were asked to run and take as many laps as possible unless they got tired. As the level increased, the duration between each beep reduced. The children were informed about this and thus were asked to increase their pace after every lap. The number of laps taken by each child was noted. $\mathrm{VO}_{2}$ max was then calculated using the linear model 2. CLASS: The questionnaire consists of 45 activities categorized into moderate- and vigorousintensity physical activities, and leisure activities which children usually perform in the entire week. The duration and frequency for leisure activities and moderate- and vigorous-intensity physical activities were entered by the children or their parents. The duration for each activity performed in a day was calculated by dividing the total duration with the total frequency for that particular activity. Thus, total duration for all activities performed in a day was added.

All the data analyses were carried out in SPSS and Microsoft Word and Excel were used to generate graphs, tables, etc. An alpha level of 0.05 was used to determine statistical significance.

\section{RESULTS}

A total of 568 children (332 males and 236 females) were recruited during the study period. Of these, 173 (98 males and 75 females) were of 10 years of age, 212 (122 males and 90 females) were aged 11 years, and 183 students (112 males and 71 females) were aged 12 years. The average age of students was 11.09 years. Average BMI of males was $16.52 \pm 3.66 \mathrm{~kg} / \mathrm{m}^{2}$ and for females was $17.12 \pm 2.46 \mathrm{~kg} / \mathrm{m}^{2}$. Average $\mathrm{VO}_{2} \max$ for students was $35.83 \mathrm{ml} / \mathrm{kg} / \mathrm{min}$. ST for students was ranging from 40 to $190 \mathrm{~min}$. There was no significant difference between ST of boys and girls.

Strong positive linear relationship between ST and BMI $(r=0.66)$ suggested an increase in BMI with increasing ST (Fig. 1). Weak positive linear relationship between the ST and WHR $(r=0.23)$ suggested that as ST increases, there is a trend of increasing WHR.

As shown in Fig. 2, there is a strong negative linear relationship between ST and cardiorespiratory fitness $\left(\mathrm{VO}_{2} \max \right)$ with a correlation coefficient of -0.77 . This suggests that as ST increases cardiorespiratory fitness reduces. This can be very critical as in this age group, children are at the risk of obesity or cardiorespiratory/ lifestyle disorders (hypertension, diabetes, and cardiac diseases).

\section{DISCUSSION}

This study was aimed to correlate ST with BMI, WHR, and cardiorespiratory fitness in children aged between 10 and 12 years. As shown in Fig. 1, there is a strong positive linear relationship between ST and BMI, suggesting that as the ST increased, there was also an increase in the BMI.

The normal ST for children is considered to be $60 \mathrm{~min}$ per day $[4,5,11]$. In our study, children with a higher BMI showed a higher ST ranging from 120 to $160 \mathrm{~min}$ per day. This suggests that children who were obese had a greater ST and vice versa as they were exposed to a greater degree of food advertising which resulted in intake of high density and nutrient-poor food. These results are in accordance with the previous studies $[9,10]$. However, a research has shown that increase in ST contributes to the improvement in academic performance due to easy access to the internet [8].

Studies have shown that TV viewing is inversely associated with intake of fruits and vegetables, despite their potential to promote health in various ways and protect against weight gain $[12,22]$. Viewing television for long periods and greater snack food consumption together contribute to increase in BMI [10]. The possible cause of increase in BMI is reduced metabolic equivalent (MET value), i.e., low metabolic rate associated with increasing ST. The MET required for watching TV is 1.0 , only slightly above the MET value for sleeping (0.9). The MET values for physical activities are much higher than that for watching TV, for example, walking (5 mph) has a MET value of 6 , jogging $(5 \mathrm{mph})$ has a MET value of 8, bicycling (13 mph) has a MET value of 9, etc. [7].

Thus, the energy expenditure while watching TV and spending time on other media are very little leading to increased risk of obesity among children [13]. As shown in Fig. 3, there is a weak positive linear relationship between ST and WHR, suggesting that as the ST increased, the WHR also increased and vice versa. A weak correlation suggests that sedentary behavior and physical activity are not always inversely correlated which means that though the level of physical activity of the child might be low, the child might not necessarily have a sedentary behavior [10]. 


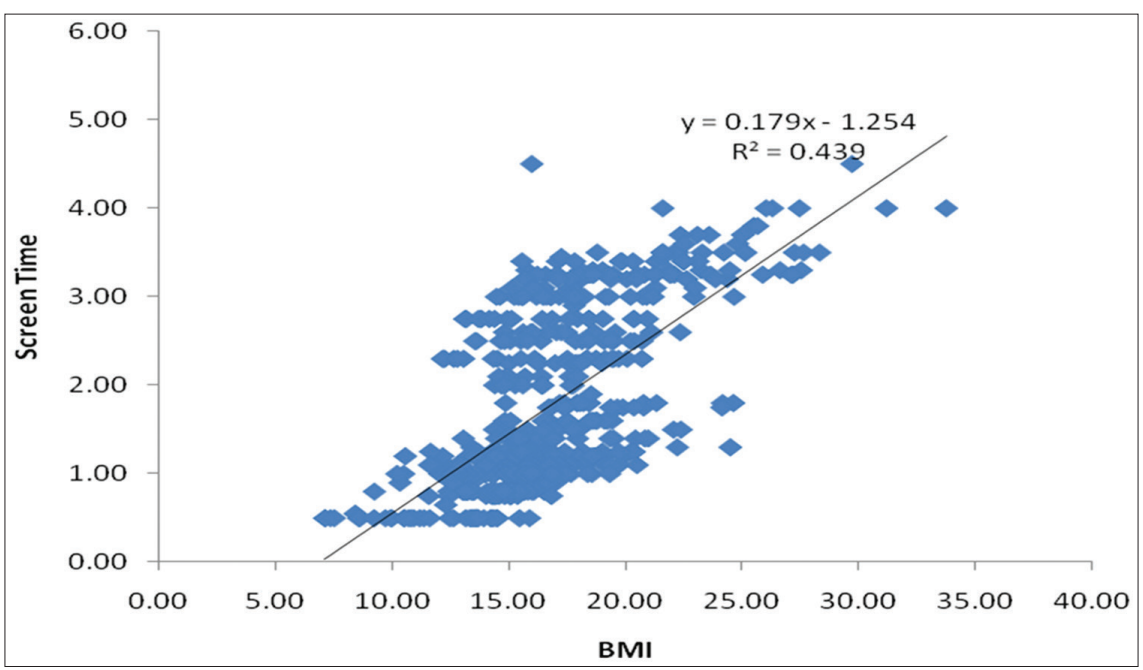

Figure 1: Correlation between body mass index and screen time

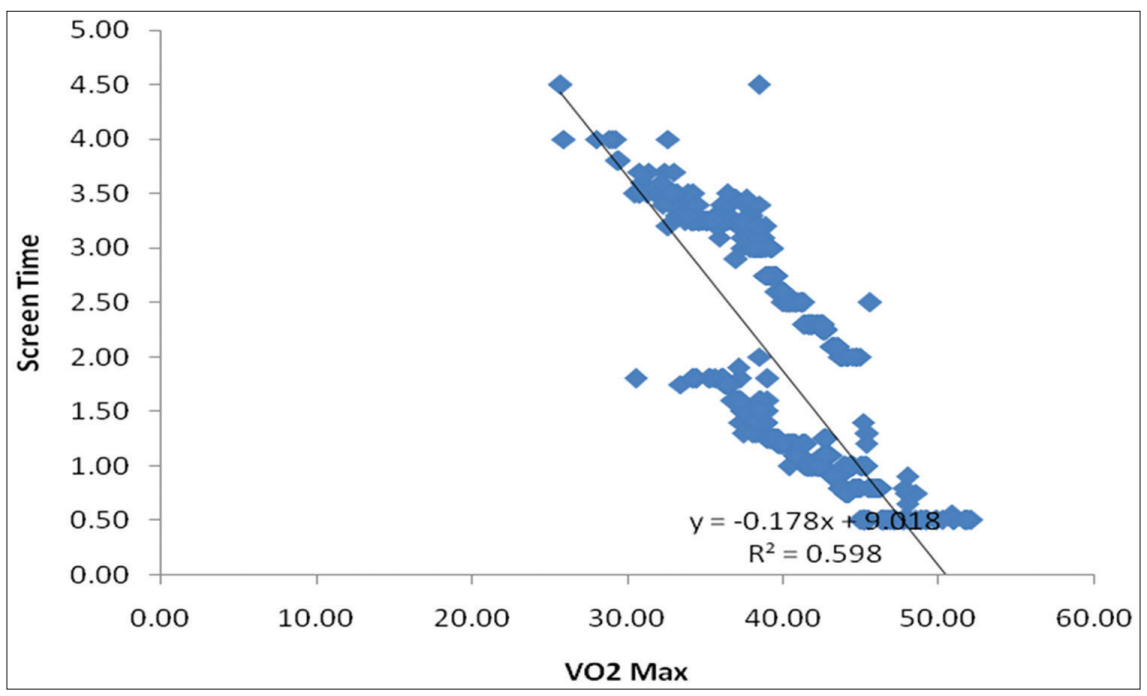

Figure 2: Correlation between screen time and cardiorespiratory fitness $\left(\mathrm{VO}_{2}\right.$ max)

A combination of low levels of active play and higher ST cannot be avoided which may increase the likelihood of obesity persistence even in adulthood [10]. Increased intake of high-energy-density food due to increased media exposure (advertising), television viewing, and playing of computer and video games in children contributes to increased risk of sedentary behavior and thus leading to obesity [8]. A possible explanation of this can be given by the intracellular pressure changes which the fat cells undergo while sitting. The fat carrying molecules-lipid droplets undergo an accelerated growth when exposed to sustained chronic pressure. Unlike the muscle and bone tissue, which get mechanically weaker with disuse, fat depots in fat cells expand when they experience sustained loading. The researchers showed that, once cells accumulated lipid droplets, the structure of the cell changed causing it to become stiffer. When these cells gain mass, they expand deforming the surrounding cells and thus forcing them to expand further [14].

The probable cause for an increase in the waist circumference is due to large-sized adipocytes present within the subcutaneous tissue around the abdomen. Thus, when there is a greater consumption of energy-rich food, there is greater accumulation of fat within the adipocytes around the abdomen [15]. Another probable cause for an increase in the waist circumference is changes in the hormonal levels, but these hormonal changes are not very significant before adolescence [16]. Thus, increasing concentration of lipids within the cells and their expansion due to sedentary lifestyle contributes to increase in fat mass around susceptible areas.

As shown in Fig. 2, there is a strong negative linear relationship between ST and cardiorespiratory fitness which suggests that as the ST increased, the level of cardiorespiratory fitness decreased and vice versa. Increased dependence on vehicles for transportation, use of mechanical and computerized technology by children contribute to a decrease in physical activity, reducing the levels of physical fitness and enhancing the risk of cardiorespiratory illnesses. This increases the chances of the child to develop high blood pressure, hyperlipidemia, elevated insulin levels, and respiratory problems such as asthma which are more common in obese children than non-obese children [17].

Various metabolic and respiratory changes normally take place during exercise. There is a decrease in levels of glycogen or glycogen sparing. Exercise increases the capacity to mobilize and oxidize fat and increases the levels of fat mobilizing and fat metabolizing enzymes. There is an increase in alveolar ventilation causing diffusion 


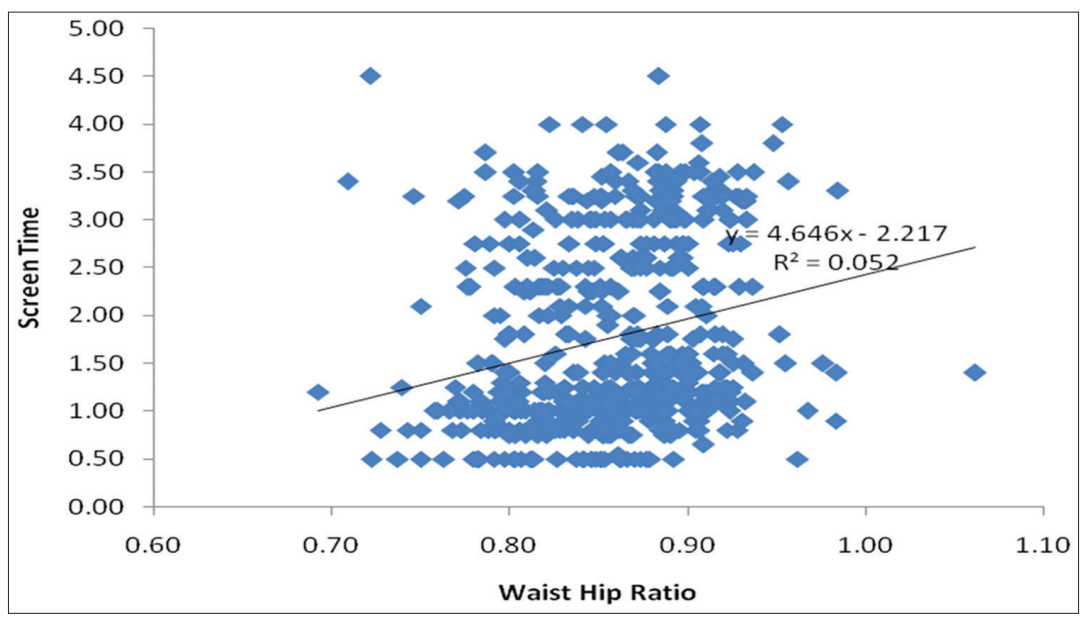

Figure 3: Correlation between screen time and waist-hip ratio

of gases (increase in $\mathrm{O}_{2}$ uptake and excretion of excess of $\mathrm{CO}_{2}$ ) across the alveolar-capillary membranes, thus increasing overall pulmonary ventilation $[7,18]$. Reduction in exercise leads to an increase in levels of fat within the blood vessels due to a reduction in fat mobilization and metabolism. Reduction of $\mathrm{O}_{2}$ uptake causes reduction in alveolar ventilation and reduction in $\mathrm{CO}_{2}$ excretion, thus reducing overall pulmonary ventilation $[2,19,20]$. All these mechanisms reduce the levels of cardiorespiratory fitness and accelerate the process of atherosclerosis [7,21]. Exercises also improve glucose tolerance by enhancing insulin sensitivity and carbohydrate metabolism, thus maintaining optimum levels of insulin and glucose.

Reduction in exercise fails to maintain these optimum levels and makes an individual susceptible to diabetes [21].Thus, an increase in energy consumptionand reduction in energy expenditure due to increased ST in children is one of the leading causes behind increased risk of obesity and reduced cardiorespiratory fitness $[10,7,22]$. The limitation of this study was that other risk factors (e.g., psychological risk factors like stress) were not measured which have significant effects on the change in eating habits.

\section{CONCLUSION}

Thus, it can be concluded that there is a significant effect of ST on children which increases the chances of obesity, reduces the level of cardiorespiratory fitness by reduction in the levels of physical activity.

\section{REFERENCES}

1. World Health Organization. Overweight and Obesity Report. Report No: 311. Geneva: World Health Organization; 2006.

2. Ranjani H, Mehreen TS, Pradeepa R, Anjana RM, Garg R, Anand K, et al. Epidemiology of childhood overweight and amp; obesity in India: A systematic review. Indian J Med Res 2016;143:160-74.

3. Pradeepa R, Anjana RM, Joshi SR, Bhansali A, Deepa M, Joshi PP, et al. Prevalence of generalized and amp; abdominal obesity in urban and amp; rural India the ICMR-INDIAB study (Phase-I) [ICMR-NDIAB-3]. Indian J Med Res 2015;142:139-50.

4. Kar SS, Kar SS. Prevention of childhood obesity in India: Way forward. J Nat Sci Biol Med 2015;6:12-7.

5. Dehghan M, Akhtar-Danesh N, Merchant AT. Childhood obesity, prevalence and prevention. Nutr J 2005;4:24.

6. Steele RM, Sluijs E, Griffin SJ, Ekelund U. Targeting sedentary time and or moderate and vigorous-intensity activity: Independent relations with adiposity in a population-based sample of 10 -yr old British children. Am J Clin Nutr 2009;90:1185.

7. Sweetser P, Johnson D, Ozdowska A, Wyeth P. Active versus passive screen time for young children. Australas J Early Child 2012;37:94-8.

8. Anderson SE, Economos C, Must A. Active play and st in US children aged 4 to 11 years in relation to socio demographic and weight status characteristics. BMC Public Health 2008;8:2, 9, 13.

9. American Diabetes Association. Physical activity exercise and diabetes. Diabetes Care 2004;27:560-2.

10. Ray M, Jat KR. Effect of electronic media on children. Indian Pediatr 2010;47:561-8.

11. Holloway D, Green L, Livingstone S. Zero to Eight. Young Children and Internet Use. London: London School of Economics; 2013. p. 4-7.

12. Shields M, Tremblay MS. Sedentary behaviour and obesity. Health Rep 2008;19:19-30

13. Wajchenberg BL. Subcutaneous and visceral adipose tissue: Their relation to the metabolic syndrome. Endocr Rev 2000;21:697-738.

14. Huang TT, Johnson MS, Figueroa-Colon R, Dwyer JH, Goran MI. Growth of visceral fat, subcutaneous abdominal fat, and total body fat in children. Obes Res 2001;9:283-9.

15. WHO. Waist Circumference and Waist Hip Ratio. Geneva: WHO; 2008.

16. Mahar MT, Guerieri AM, Hanna MS, Kemble CD. Estimation of aerobic fitness from 20-m multistage shuttle run test performance. Am J Prev Med 2011;41:S117-23.

17. Kisner C, Colby L. Principles of Aerobic Exercise. Therapeutic Exercise. Philadelphia, PA. $5^{\text {th }}$ ed. 2007. p. 241-3.

18. Boynton-Jarrett R, Thomas TN, Peterson KE, Wiecha J, Sobol AM, Gortmaker SL, et al. Impact of television viewing patterns on fruit and vegetable consumption among adolescents. Pediatrics 2003;112:1321-6.

19. Tremblay MS, Colley RC, Saunders TJ, Healy GN, Owen N. Physiological and health implications of a sedentary lifestyle. Appl Physiol Nutr Metab 2010;35:725-40.

20. Silva G, Oliveira NL, Aires L, Mota J, Oliveira J, Ribeiro JC. Calculation and validation of models for estimating $\mathrm{VO}_{2}$ max from the 20 -m shuttle run test in children and adolescents. Arch Exerc Health Dis 2012;3:145-52.

21. Reading K, Carr D. Obesity and Overweight in Oxford County Preschoolers. Woodstock, ON: Oxford County; 2011. p. 3-4, 8-11.

22. Salmon J, Timperio A, Telford A, Carver A, Crawford D. Association of family environment with children's television viewing and with low level of physical activity. Obes Res 2005;13:1939-51.

Funding: None; Conflict of Interest: None Stated.

How to cite this article: Agre S, Agrawal R, Alirajpurwala A. Screen time evaluation, association with obesity, and cardiorespiratory fitness among children aged 10-12 years. Indian J Child Health. 2019; 6(7):361-364.

Doi: 10.32677/IJCH.2019.v06.i07.008 